\title{
Divergência genética em espécies e híbridos interespecíficos de Physalis baseada em
}

\section{caracteres morfoagronômicos}

\author{
Divergence genetic in Physalis species and interspecific hybrids based on morphoagronomic \\ characters \\ Divergencia genética en especies e híbridos interespecíficos de Physalis basados en caracteres \\ morfoagronómicos
}

\author{
André Dutra Silva Júnior \\ ORCID: https://orcid.org/0000-0002-7909-1034 \\ Universidade Federal de Viçosa, Brasil \\ E-mail: andredr018@gmail.com \\ André Ricardo Zeist \\ ORCID: https://orcid.org/0000-0003-1651-4797 \\ Universidade Federal de Santa Catarina, Brasil \\ E-mail: andre.zeist@ufsc.br \\ Murilo Henrique Souza Leal \\ ORCID: https://orcid.org/0000-0001-9219-3695 \\ Universidade do Oeste Paulista, Brasil \\ E-mail: muriloleal8@gmail.com \\ Joana Nascimento Merces de Oliveira \\ ORCID: https://orcid.org/0000-0002-5452-8412 \\ Universidade do Oeste Paulista, Brasil \\ E-mail: ojoana140@gmail.com \\ Guilherme José Almeida Oliveira \\ ORCID: https://orcid.org/0000-0003-0068-1259 \\ Universidade do Oeste Paulista, Brasil \\ E-mail: guilhermejaost@hotmail.com \\ Bruno Da Rocha Toroco \\ ORCID: https://orcid.org/0000-0002-8908-687X \\ Universidade do Oeste Paulista, Brasil \\ E-mail: bruno-taroco@ hotmail.com \\ Daniel Fernandes da Silva \\ ORCID: https://orcid.org/0000-0003-2105-5839 \\ Universidade Estadual do Oeste do Paraná, Brasil \\ E-mail: daniel_eafi@yahoo.com.br \\ Alison Fernando Nogueira \\ ORCID: https://orcid.org/0000-0003-4395-3218 \\ Universidade Estadual de Londrina, Brasil \\ E-mail: alison.fernando@uel.br
}

\begin{abstract}
Resumo
Physalis L. é um dos gêneros mais importantes da família Solanaceae, contendo 120 espécies botanicamente identificadas. As espécies de Physalis possuem uma grande variedade genética, devido ao elevado número de espécies botanicamente identificadas, que garante características peculiares de interesse econômico. Apesar do conhecimento dessas características, pouco se tem feito para o melhoramento genético dessa pequena fruta. Para se iniciar o melhoramento é necessário realizar a análise da diversidade genética em bancos de germoplasma. Desse modo, objetivou-se explorar parâmetros morfoagronômicos de sete espécies e vinte e nove híbridos interespecíficos de Physalis, visando contribuir para programas de melhoramento genético. Utilizou-se sete espécies: Physalis angulata, Physalis ixocarpa, Physalis pruinosa, Physalis peruviana, Physalis pubescens, Physalis mínima e Physalis daturaefolia e 29 híbridos interespecíficos. Para a caracterização morfoagronômicos, foi utilizada uma lista de 42 descritores, sendo 22 variáveis quantitativas e 20 qualitativas. Utilizando o agrupamento hierárquico de Ward com base na distância de Mahalanobis, observamos a formação de cinco grupos com parentes próximos em relação aos dados qualitativos. O método de Mojena (1977) indicou a formação de cinco grupos distintos. A análise de componentes principais (PCA) explicou $63.01 \%$ da variação total existente entre as sete espécies e os 29 híbridos de Physalis por meio dos dois primeiros componentes principais (PC1 e PC2). Em base dos caracteres explorados foram diferenciados cinco grupos quantitativos e qualitativos distintos. Os híbridos de Physalis foram superiores para maioria das variáveis quantitativas.
\end{abstract}


Palavras-chave: Análise multivariada; Melhoramento de plantas; Diversidade genética; Similaridade; Similaridade genética.

\begin{abstract}
Physalis L. is one of the most important genera of the Solanaceae family, containing 120 species identified botanically. Physalis species have a great genetic, variety due to the high number of botanically identified species, which guarantees peculiar characteristics of economic interest. Despite the knowledge of these characteristics, little has been done for the genetic improvement of this small fruit. To start the improvement, it is necessary to carry out the analysis of genetic diversity in germplasm banks. Thus, the objective was to explore morphoagronomic parameters of seven species and twenty-nine interspecific Physalis hybrids, aiming to contribute to genetic improvement programs. Seven species were used: Physalis angulata, Physalis ixocarpa, Physalis pruinosa, Physalis peruviana, Physalis pubescens, Physalis mínima and Physalis daturaefolia and 29 hybrids interspecific. For the morphoagronomic characterization, a list of 42 descriptors was used, with 22 quantitative and 20 qualitative variables. Using Ward's hierarchical grouping based on Mahalanobis distance, we observed the formation of five groups with close relatives in relation to the qualitative data. Mojena's method (1977) indicated the formation of five distinct groups. Principal component analysis (PCA) explained $63.01 \%$ of the total variation between the seven species and the 29 Physalis hybrids through the first two principal components (PC1 and PC2). Based on the characters explored, five distinct quantitative and qualitative groups were differentiated. Physalis hybrids were superior for most quantitative variables.
\end{abstract}

Keywords: Multivariate analysis; Plant breeding; Genetic diversity; Similarity; Genetic similarity.

\title{
Resumen
}

Physalis L. es uno de los géneros más importantes de la familia de las solanáceas, que contiene 120 especies identificadas botanicamente. Las especies de Physalis presentan una gran variedad genética, debido al elevado número de especies botánicamente identificadas, lo que garantiza características peculiares de interés económico. A pesar del conocimiento de estas características, poco se ha hecho por la mejora genética de este pequeño fruto. Para iniciar el mejoramiento es necesario realizar el análisis de diversidad genética en bancos de germoplasma. Así, el objetivo fue explorar parámetros morfoagronómicos de siete especies y veintinueve híbridos interespecíficos de Physalis, con el objetivo de contribuir a los programas de mejoramiento genético. Se utilizaron siete especies: Physalis angulata, Physalis ixocarpa, Physalis pruinosa, Physalis peruviana, Physalis pubescens, Physalis mínima y Physalis daturaefolia y 29 híbridos interespecíficos. Para la caracterización morfoagronómica se utilizó una lista de 42 descriptores, con 22 variables cuantitativas y 20 cualitativas. Utilizando el agrupamiento jerárquico de Ward basado en la distancia de Mahalanobis, observamos la formación de cinco grupos con parientes cercanos en relación a los datos cualitativos. El método de Mojena (1977) indicó la formación de cinco grupos distintos. El análisis de componentes principales (PCA) explicó el 63,01\% de la variación total entre las siete especies y los 29 híbridos de Physalis a través de los dos primeros componentes principales (PC1 y PC2). Con base en los Caracteres Explotado, se diferenciaron cinco grupos cuantitativos y cualitativos distintos. Los híbridos de Physalis fueron superiores para la mayoría de las variables cuantitativas.

Palabras clave: Análisis multivariado; Fitomejoramiento; Diversidad genética; Similitud; Similitud genética.

\section{Introdução}

Physalis L., um dos gêneros mais importantes da família Solanaceae, contém 120 espécies botanicamente identificadas, que são principalmente distribuídas nas regiões tropicais e temperadas da América, embora existam algumas espécies na Eurásia e Sudeste Asiático (Abdel-Ghani et al., 2015; Martínez, 1998; Sun et al., 2017; Wei et al., 2017; Whitson \& Manos, 2005). Entre as espécies mais conhecidas por seu cultivo e emprego na alimentação humana estão a Physalis peruviana, P. pubescens, $P$. ixocarpa e $P$. pruinosa. Às espécies $P$. angulata, $P$. alkekengi e $P$. minima é atribuído valor medicinal e ainda valor ornamental à $P$. alkekengi pela coloração vermelha intensa de seu cálice (Fukushima et al., 2016).

As espécies de Physalis possuem uma grande variedade genética fenólica devido ao seu grande número de espécies botanicamente identificadas (Medina-Medrano et al., 2015). E vem despertando o interesse científico, tanto no sentido de melhorar o desempenho agronômico da cultura, quanto na identificação fitoquímica e busca por metabólitos secundários para uso farmacológico (Bonilla Betancourt et al., 2008; Trevisani et al., 2016). Apesar do grande número de espécies existentes e da imensa variabilidade genética verificada nos bancos de germoplasmas mantidos em instituições de pesquisa, a existência de cultivares comerciais é escassa (Suescún et al., 2011). 
A grande diversidade genética entre as espécies de Physalis garante a umas características peculiares de interesse econômico, como por exemplo coloração e presença de compostos bioativos. Apesar do conhecimento dessas características e do consumo de Physalis há muito tempo em alguns países como México e Colômbia, pouco se tem feito para o melhoramento genético desta frutífera (Silva et al., 2018; Suescún et al., 2011). Adicionalmente na maioria dos locais onde é consumida ainda são plantadas as espécies locais, com variação entre as plantas, predominando o cultivo de $P$. peruviana (Samuels, 2015).

Estudos agronômicos existentes ainda não caracterizaram os genótipos de Physalis ao nível de cultivar na maioria das espécies (Araujo, 2012). Também são inexistentes relatos sobre a exploração de híbridos interespecíficos em Physalis e os poucos estudos existentes visaram principalmente a elucidação de aspectos filogenéticos (Azeez \& Faluyi, 2018; Cely et al., 2015).

A exploração da variabilidade genética é o principal ponto de partida para qualquer melhoramento genético (Debbi et al., 2018; Sobral et al., 2012). Portanto, a análise da diversidade genética em bancos de germoplasma é o componente principal para a escolha de genótipos com características desejáveis que possam promover ganhos genéticos em gerações futuras (Flávia Barbosa Abreu, 2005; Carmona et al., 2015; Nahak et al., 2018; Pandey et al., 2020). A caracterização morfológica é a forma mais acessível de quantificar sua diversidade genética (Spooner et al., 2005).

Traços morfológicos têm sido usados para estimar a diversidade genética e o desenvolvimento de cultivares, uma vez que fornecem uma maneira simples de quantificar a variação genética (Fufa et al., 2005). A grande variabilidade genética do Physalis permite diversidade em morfologia da planta e variações no tamanho, formato e características químicas dos frutos (Aliero \& Usman, 2016). A Physalis possui algumas peculiaridades edafoclimáticas e isso não permite seu amplo cultivo e consumo no mundo (Fischer et al., 2014; Salazar-Gutierrez et al., 2008). A Physalis philadelphica apesar de possuir variabilidade morfológica (Zamora-Tavares et al., 2015) e ser uma das espécies de maior e mais antigo consumo no México, seu melhoramento ainda se restringe a poucas cultivares, como 'San Martín', 'Tecozautla', 'Rendidora' e 'Diamante' (Benito-Bautista et al., 2016). No entanto, a propagação sexuada permite aprimoramento no desenvolvimento de genótipos e pode possibilitar o surgimento de plantas mais produtivas (Silva et al., 2016).

Estávamos interessados em avaliar a diversidade genética do germoplasma de Physalis usando características potencialmente úteis para programas de melhoramento. Com isso objetivou-se explorar parâmetros morfoagronômicos de sete espécies e vinte e nove híbridos interespecíficos de Physalis, visando contribuir para programas de melhoramento futuros e geração de genótipos que melhor atendam às necessidades dos produtores e exigências dos consumidores.

\section{Metodologia}

\subsection{Local de condução dos experimentos}

O trabalho foi realizado na área experimental do Centro de Estudos em Olericultura e Fruticultura do Oeste Paulista CEOFOP, localizado na Universidade do Oeste Paulista - UNOESTE, coordenadas $22^{\circ} 07^{\prime \prime}$ de latitude Sul e $51^{\circ} 27^{\prime \prime}$ de longitude Oeste e a uma altitude de 430 metros. O clima, segundo a classificação de Köppen, é do tipo Cwa, com temperatura média anual de $25^{\circ} \mathrm{C}$ e com precipitação média anual de 1400 a $1500 \mathrm{~mm}$, caracterizado por dois períodos distintos, um chuvoso de outubro a março e outro de baixo índice pluvial de abril a setembro.

\subsection{Material experimental e delineamento}

Utilizou-se um acesso das espécies Physalis peruviana, P. ixocarpa, P. minima, P. pubescens, $P$. angulata, $P$. pruinosa e $P$. daturaefolia e 29 combinações híbridas resultantes dos cruzamentos dessas espécies (Tabela 1). As sementes das sete espécies de Physalis foram doadas pela coleção didática instalada no pomar da Universidade Estadual do Oeste do Paraná (Unioeste). As plantas foram conduzidas em delineamento experimental de blocos com os tratamentos ao acaso com quatro repetições, constituída em cada parcela por quatro plantas. 
Tabela 1. Híbridos interespecíficos obtidos através do cruzamento de espécies de Physalis.

\begin{tabular}{|c|c|}
\hline \multicolumn{2}{|c|}{ Híbridos interespecíficos } \\
\hline 1. $\mathrm{F}_{1}(P$. pubescens $\times P$. angulata $)$ & 16. $\mathrm{F}_{1}(P$. angulata $\times P$. ixocarpa $)$ \\
\hline 2. $\mathrm{F}_{1}(P$. peruviana $\times P$. pubescens $)$ & 17. $\mathrm{F}_{1}(P$. angulata $\times$ P. pruinosa $)$ \\
\hline 3. $\mathrm{F}_{1}(P$. peruviana $\times P$. pruinosa $)$ & 18. $\mathrm{F}_{1}(P$. angulata $\times P$. mínima $)$ \\
\hline 4. $\mathrm{F}_{1}(P$. pubescens $\times P$. pruinosa $)$ & 19. $\mathrm{F}_{1}(P$. pubescens $\times P$. peruviana $)$ \\
\hline 5. $\mathrm{F}_{1}($ P. ixocarpa $\times$ P. Pruinosa $)$ & 20. $\mathrm{F}_{1}(P$. pubescens $\times P$. ixocarpa $)$ \\
\hline 6. $\mathrm{F}_{1}(P$. ixocarpa $\times P$. mínima $)$ & 21. $\mathrm{F}_{1}(P$. mínima $\times P$. pruinosa $)$ \\
\hline 7. $\mathrm{F}_{1}(P$. ixocarpa $\times P$. angulata $)$ & 22. $\mathrm{F}_{1}(P$. peruviana $\times P$. ixocarpa $)$ \\
\hline 8. $\mathrm{F}_{1}(P$. pubescens $\times$ P. mínima $)$ & 23. $\mathrm{F}_{1}(P$. angulata $\times P$. pubescens $)$ \\
\hline 9. $\mathrm{F}_{1}(P$. mínima $\times P$. angulata $)$ & 24. $\mathrm{F}_{1}(P$. daturifolia $\times P$. ixocarpa $)$ \\
\hline 10. $\mathrm{F}_{1}(P$. peruviana $\times P$. mínima $)$ & 25. $\mathrm{F}_{1}(P$. daturifolia $\times P$. angulata $)$ \\
\hline 11. $\mathrm{F}_{1}(P$. angulata $\times P$. peruviana $)$ & 26. $\mathrm{F}_{1}(P$. daturifolia $\times P$. peruviana $)$ \\
\hline 12. $\mathrm{F}_{1}(P$. mínima $\times P$. pubescens $)$ & 27. $\mathrm{F}_{1}(P$. daturifolia $\times P$. pubescens $)$ \\
\hline 13. $\mathrm{F}_{1}(P$. pruinosa $\times$ P. pubescens $)$ & 28. $\mathrm{F}_{1}(P$. peruviana $\times P$. angulata $)$ \\
\hline 14. $\mathrm{F}_{1}(P$. pruinosa $\times P$. angulata $)$ & 29. $\mathrm{F}_{1}(P$. angulata $\times P$. peruviana $)$ \\
\hline 15. $\mathrm{F}_{1}(P$. pruinosa $\times P$. mínima $)$ & \\
\hline
\end{tabular}

Fonte: Autores.

\subsection{Condução e manejo experimental}

As mudas dos híbridos interespecíficos e dos genitores foram obtidas a partir da semeadura em bandejas de poliestireno expandido com 128 células, contendo substrato comercial a base da casca de pinus bioestabilizada e mantidas em casa de vegetação até atingirem quatro folhas completamente expandidas. A partir de então a condução das plantas foi no campo, em área onde foi realizada aração no solo e feito o preparo de canteiros de 1,0 metro de largura utilizando rotoencanteirador. O solo do local foi corrigido e aplicado adubo de acordo com a necessidade indicada na análise do solo, seguindo a recomendação para a cultura do tomateiro, para uma expectativa de produção de $20 \mathrm{t} \mathrm{ha}^{-1}$, conforme realizado por Muniz et al. (2011).

Para o plantio foi adotado espaçamento de cultivo de $1,00 \mathrm{~m}$ entre plantas e 1,50 m entre fileiras. As plantas foram conduzidas com duas hastes principais, inclinadas no ângulo de $60^{\circ}$ e tutoradas com estaquia. e um fio de arame na altura de $1,70 \mathrm{~m}$ do nível do solo, metodologia adaptada por Muniz et al. (2011).

\subsection{Parâmetros explorados}

Para a caracterização morfoagronômicos, foi utilizada uma lista de 42 descritores adaptados da metodologia de (González et al., 2008), sendo avaliadas 22 variáveis quantitativas (Tabela 1) e 20 qualitativas (tabela 2). Durante o pleno florescimento foram avaliadas as características relacionadas as flores e durante o desenvolvimento e maturação dos frutos as características relacionadas ao caule e aos frutos. 
Tabela 2. Caracteres morfoagronômicos quantitativos avaliados nas espécies de Physalis L. e respectivos híbridos interespecíficos.

\begin{tabular}{|c|c|}
\hline Caracteres morfoagronômicos & Época de avaliação \\
\hline \multicolumn{2}{|c|}{ Flores } \\
\hline (1) Número de pétalas & Pleno florescimento \\
\hline (2) Número de sépalas & Pleno florescimento \\
\hline (3) Número de anteras & Pleno florescimento \\
\hline (4) Comprimento do estigma & Pleno florescimento \\
\hline (5) Número de flores por racemo & Pleno florescimento \\
\hline \multicolumn{2}{|c|}{ Folhas } \\
\hline (6) número de folhas & Pegamento dos frutos \\
\hline (7) Comprimento da folha & Pegamento dos frutos \\
\hline (8) Largura da folha & Pegamento dos frutos \\
\hline \multicolumn{2}{|c|}{ Caule } \\
\hline (9) Diâmetro da haste principal & Desenvolvimento dos frutos \\
\hline (10) Número de hastes laterais & Desenvolvimento dos frutos \\
\hline (11) Número de nós & Desenvolvimento dos frutos \\
\hline (12) Altura da planta & Desenvolvimento dos frutos \\
\hline (13) Comprimento do entrenó & Desenvolvimento dos frutos \\
\hline \multicolumn{2}{|c|}{ Frutos } \\
\hline (14) Número de frutos & Maturação dos frutos \\
\hline (15) Produção de frutos & Maturação dos frutos \\
\hline (16) Massa média de frutos & Maturação dos frutos \\
\hline (17) Diâmetro horizontal & Maturação dos frutos \\
\hline (18) Diâmetro vertical & Maturação dos frutos \\
\hline (19) Número de lócus & Maturação dos frutos \\
\hline (20) Número de sementes & Maturação dos frutos \\
\hline (21) Sólidos solúveis totais & Maturação dos frutos \\
\hline (22) Massa seca de frutos & Maturação dos frutos \\
\hline
\end{tabular}

Fonte: Caracteres modificados de González et al. (2008). 
Tabela 3. Caracteres morfoagronômicos qualitativos avaliados nas espécies de Physalis L. e respectivos híbridos interespecíficos.

\begin{tabular}{|c|c|}
\hline Variável & Escala de notas \\
\hline \multicolumn{2}{|r|}{ Flores } \\
\hline (1) Cor do caule & 1- Verde; 2- púrpura \\
\hline (2) Pubescência & 1- Ausente; 2- Fraca; 3- Média; 4- Abundante \\
\hline (3) Antocianina & 1- Ausente; 2- Presente \\
\hline \multicolumn{2}{|r|}{ Folhas } \\
\hline (4) Forma da lâmina & 1- Lanceolada; 2- Cordada; 3- Assimétrica \\
\hline (5) Forma da margem & $\begin{array}{l}\text { 1- Serrada; 2- Ondulada; 3- Repando; 4- Ondulada; 5- Simuada; 6- } \\
\text { Eroso }\end{array}$ \\
\hline (6) Forma da base & 1- Inequilátera; 2- Cuneada; 3- Oblíqua; 4- Cordada; 5- Subcordada \\
\hline (7) Forma do ápice & 1- Agudo; 2- Apiculado; 3- Acuminado \\
\hline (8) Pubescência ao feixe & 1- Ausente; 2- Fraca; 3- Média; 4- Abundante \\
\hline (9) Pubescência ao redor & 1- Ausente; 2- Fraca; 3- Média; 4- Abundante \\
\hline (10) Antocianina & 1- Ausente; 2- Presente. \\
\hline \multicolumn{2}{|r|}{ Caule } \\
\hline (11) Posição da flor & 1- Ereta; 2- Pêndula. \\
\hline (12) Cor da corola & 1- Amarelo escuro; 2- Amarelo Esbranquiçado; 3- Azul \\
\hline (13) Cor das manchas da corola & 1- Café; 2- Marrom; 3- Azul claro \\
\hline (14) Cor do cálice imaturo & $\begin{array}{l}\text { 1- Verde sem antocianina; } 2 \text { - Verde com antocianina leve; } 3 \text { - Verde } \\
\text { com antocianina forte }\end{array}$ \\
\hline (15) cor do pedicelo & 1- Verde; 2- Purpura \\
\hline (16) Tipo de cálice & 1- Acrescente; 2- Não-crescente \\
\hline (17) Forma do Cálice & 1- Globoso; 2- Alongado; 3- Levemente achatado; 4- Achatado \\
\hline (18) Divisão do cálice & 1- Presente; 2 - Ausente \\
\hline
\end{tabular}

\section{Frutos}

(19) Cor do fruto imaturo

1- Amarelo; 2- Verde; 3- Verde claro; 4- Roxo; 5- Verde Amarelado; 6-

(20) Cor do fruto maduro

Verde + manchas; 7- Amarelo + manchas

Fonte: Caracteres modificados de González et al. (2008).

\subsection{Análise estatística}

Os dados foram verificados quanto à normalidade e homogeneidade das variâncias por meio dos testes de Shapiro-Wilk e Barttlet, respectivamente e quando atendidos esses pressupostos submetidos a análise de variância. Em seguida foram realizadas análises de correlação de Pearson e com os dados quantitativos, o agrupamento hierárquico de Ward utilizando a distância de euclidiana e análises de componentes principais. Foi realizado um dendograma entre os dados qualitativos e quantitativos, pelo Agrupamento Ward, distância genética euclidiana. Essas análises foram realizadas pelo programa computacional R (R Core Team, 2018) por meio dos pacotes ggplot2 (Package T. 2015), FactoMineR (Lê, Josse, \& Husson, 2008) e cluster (Maechler et al., 2019), tidyverse (Wickham et al., 2019), RColorBrewer e corrplot (Wei et al., 2017).

\section{Resultados}

\subsection{Associação entre dendrogramas (tanglegram)}

A comparação dos dendrogramas obtidos a partir dos dados qualitativos e quantitativos pode ser verificada no tanglegram apresentado na Figura 1. Podemos observar que não houve concordância dos agrupamentos hierárquicos de Ward utilizando os dados qualitativos e quantitativos. A não concordância entre ambos os agrupamentos foi confirmada pelo teste de Mantel $\left(r_{m}\right)$, uma vez que não houve correlação significativa entre as ambas matrizes de distância $\left(r_{m}=0.12 ; p=0.10\right)$. 
Utilizando o agrupamento hierárquico de Ward com base na distância de Mahalanobis, observamos a formação de cinco grupos com parentes próximos em relação aos dados qualitativos (Figura 1). O cluster (I) é composto pela espécie $P$. daturifolia e cinco híbridos, sendo subdividido em dois subcluster com coeficiente de similaridade de 1000. O cluster (II) é formado pelas espécies $P$. pruinosa, $P$. mínima e três híbridos, também é subdividido em dois subcluster com coeficiente de similaridade de 1000. O cluster (III) é formado pela espécie $P$. angulata e seis híbridos, sendo subdividido por três subcluster com coeficiente de similaridade de 2000. Já o Cluster (IV) é o maior grupo formado por $P$. pubescens e $P$. peruviana e doze híbridos com características qualitativas semelhantes, sendo subdividido por cinco subcluster com coeficiente de similaridade de 2800. E por fim o Cluster (V) abrangeu a espécie P. ixocarpa e três híbridos com características semelhantes, sendo subdividido por dois subcluster e coeficiente de similaridade de 5000 .

Os agrupamentos construídos pelo método de Ward para os dados quantitativos, obteve a formação de cinco grupos com parentes próximos (Figura 1). O Cluster (I) é formado pelas espécies $P$. angulata e $P$. ixocarpa e seis híbridos, sendo subdividido em dois subcluster com coeficiente de similaridade 4. O cluster (II) é formado por quatro híbridos e tem coeficiente de similaridade de 5. O cluster (III) é formado pela espécie $P$. daturifolia e cinco híbridos, sendo subdividido em três subcluster com coeficiente de similaridade de 5. Já o Cluster (IV) é o maior grupo formado pelas espécies $P$. pruinosa e $P$. mínima e doze híbridos, sendo subdividido por seis subcluster com coeficiente de 4 a 5. E por fim o Cluster (V) abrangeu P. pubescens e $P$. peruviana e dois híbridos, sendo subdividido por dois subcluster e com coeficiente de similaridade de 3 . 
Figura 1. Dendrograma obtido pelo método de Ward baseado na matriz de dissimilaridade dos descritores morfológicos qualitativos e quantitativos em espécies e híbridos de Physalis. 1. $\mathrm{F}_{1}(P$. pubescens $\times$ P. angulata $), 2 . \mathrm{F}_{1}(P$. peruviana $\times P$. pubescens $),$ 3. $\mathrm{F}_{1}(P$. peruviana $\times P$. pruinosa $)$, 4. $\mathrm{F}_{1}(P$. pubescens $\times P$. pruinosa $)$, 5. $\mathrm{F}_{1}(P$. ixocarpa $\times P$. pruinosa $)$, 6. $\mathrm{F}_{1}(P$. ixocarpa $\times P$. mínima $),$ 7. $\mathrm{F}_{1}(P$. ixocarpa $\times P$. angulata $), 8 . \mathrm{F}_{1}(P$. pubescens $\times P$. mínima $), 9 . \mathrm{F}_{1}(P$. mínima $\times P$. angulata $), 10$. $\mathrm{F}_{1}(P$. peruviana $\times$ P. mínima $)$, 11. $\mathrm{F}_{1}(P$. angulata $\times P$. peruviana $)$, 12. $\mathrm{F}_{1}(P$. mínima $\times P$. pubescens $)$, 13. $\mathrm{F}_{1}(P$. pruinosa $\times P$. pubescens $),$ 14. $\mathrm{F}_{1}(P$. pruinosa $\times P$. angulata $), 15 . \mathrm{F}_{1}(P$. pruinosa $\times P$. mínima $), 16 . \mathrm{F}_{1}(P$. angulata $\times P$. ixocarpa $), 17 . \mathrm{F}_{1}(P$. angulata $\times P$. pruinosa $),$ 18. $\mathrm{F}_{1}(P$. angulata $\times P$. mínima $)$, 19. $\mathrm{F}_{1}(P$. pubescens $\times P$. peruviana $)$, 20. $\mathrm{F}_{1}(P$. pubescens $\times P$. ixocarpa $),$ 21. $\mathrm{F}_{1}(P$. mínima $\times P$. pruinosa $), 22 . \mathrm{F}_{1}(P$. peruviana $\times P$. ixocarpa $), 23 . \mathrm{F}_{1}(P$. angulata $\times P$. pubescens $), 24 . \mathrm{F}_{1}(P$. daturifolia $\times P$. ixocarpa $), 25 . \mathrm{F}_{1}(P$. daturifolia $\times P$. angulata $), 26 . \mathrm{F}_{1}(P$. daturifolia $\times P$. peruviana $), 27 . \mathrm{F}_{1}(P$. daturifolia $\times P$. pubescens $),$ 28. $\mathrm{F}_{1}(P$. peruviana $\times$ P. angulata $), 29 . \mathrm{F}_{1}(P$. angulata $\times$ P. peruviana $)$.

\section{Qualitativo}

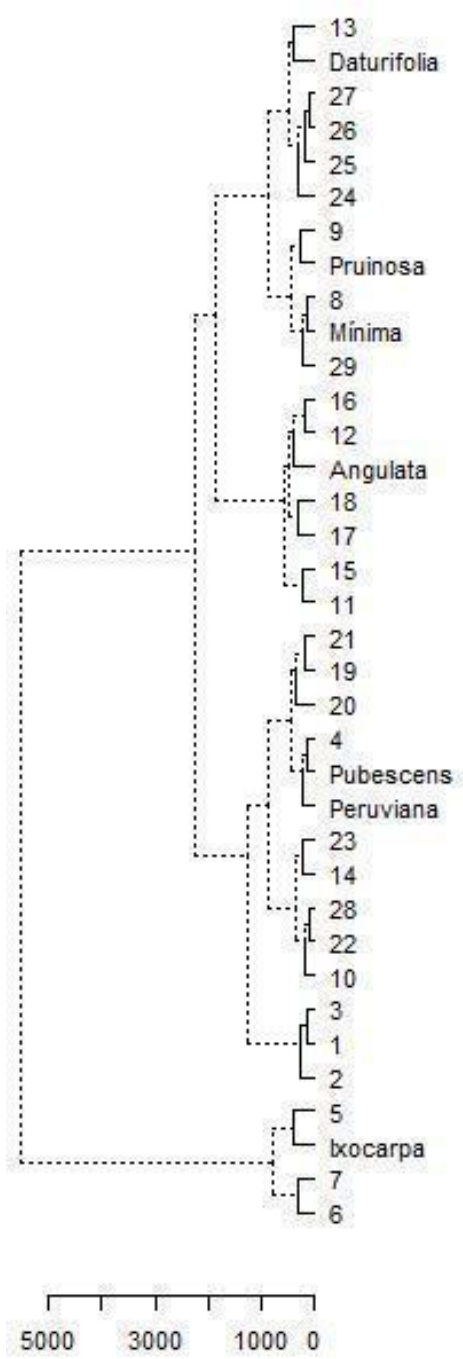

\section{Quantitativo}
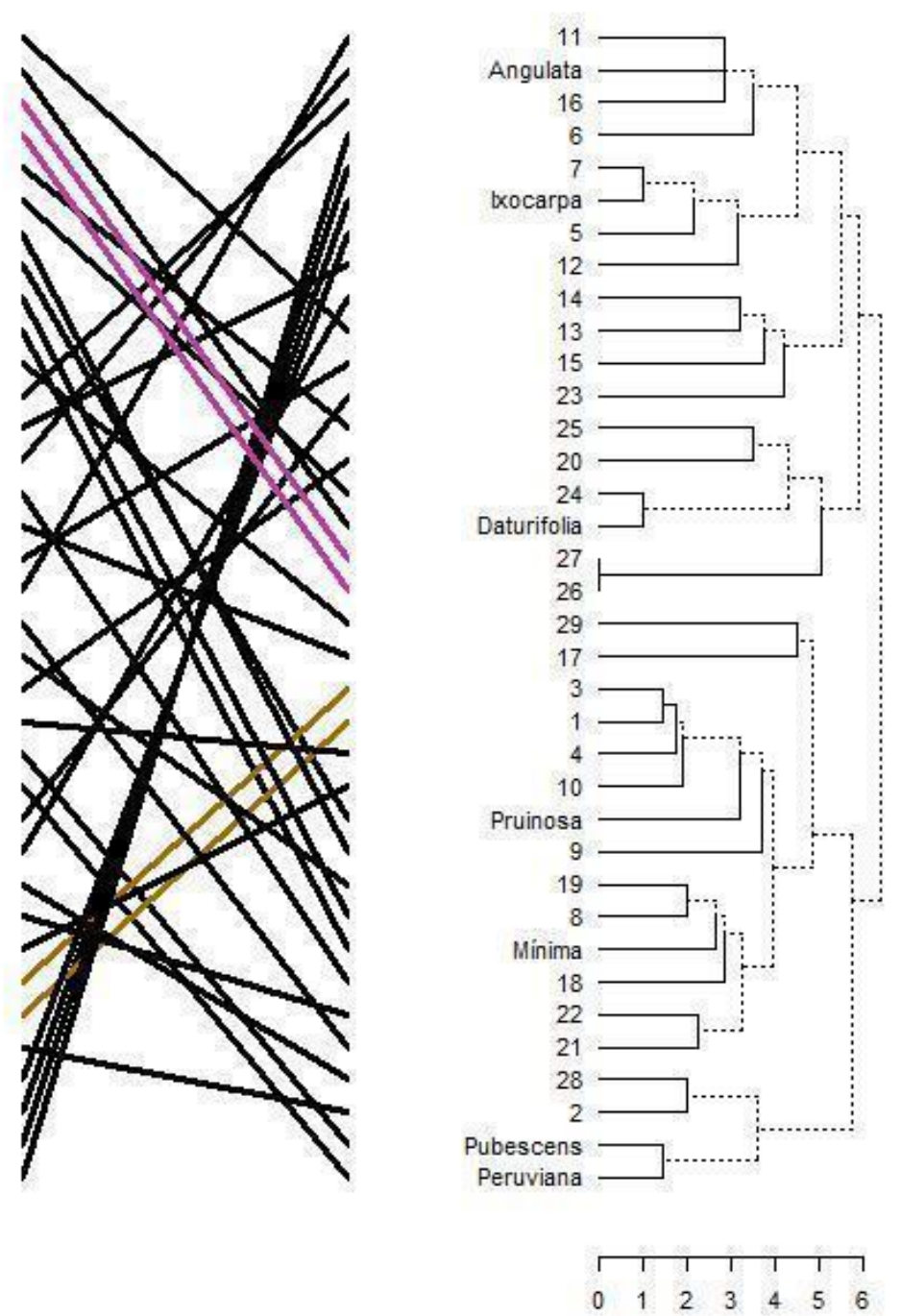

Fonte: Autores.

\subsection{Dendrograma e análise de componentes quantitativos}

O dendrograma obtido pelo método de Ward (1963) é apresentado na (Figura 2). Aqueles que possuem maiores valores foram representados pelos tons vermelhos e os metabólitos com menor intensidade foram representados pelos tons de beje claro. 
O método de Mojena (1977) indicou a formação de cinco grupos distintos. O grupo (I) é composto pela espécie $P$. ixocarpa e os híbridos $\mathrm{F}_{1}(P$. ixocarpa $\times P$. angulata $), \mathrm{F}_{1}(P$. ixocarpa $\times P$. pruinosa $)$ e $\mathrm{F}_{1}(P$. ixocarpa $\times P$. mínima $)$. Esse grupo destacou-se dos demais por apresentar as maiores médias para as características LS, NF, PF, MF, DV, DH e MSF. O Grupo (II) foi formado pela espécie $P$. daturifolia e os híbridos $\mathrm{F}_{1}(P$. daturifolia $\times P$. ixocarpa $), \mathrm{F}_{1}(P$. daturifolia $\times P$. pubescens $), \mathrm{F}_{1}(P$. daturifolia $\times$ $P$. angulata $)$ e $\mathrm{F}_{1}(P$. daturifolia $\times P$. peruviana). Esses caracterizados por apresentar as melhores médias nos parâmetros MDD, NHL, STL, CE, CL e LL. Em seguida o grupo (III) foi integrado pelas espécies $P$. peruviana e $P$. pubescens e os híbridos $\mathrm{F}_{1}(P$. pubescens $\times P$. pruinosa $), \mathrm{F}_{1}(P$. peruviana $\times P$. pruinosa $), \mathrm{F}_{1}(P$. pubescens $\times P$. peruviana $), \mathrm{F}_{1}(P$. pubescens $\times$. angulata $)$, $\mathrm{F}_{1}(P$. peruviana $\times P$. pubescens $)$ e $\mathrm{F}_{1}(P$. peruviana $\times P$. angulata $)$ e caracterizados por apresentar valores intermediários para todas as características avaliadas. O mesmo aspecto observado no grupo (IV) sendo o maior agrupamento e composto pelas espécies $P$. pruinosa e $P$. mínima e os híbridos $\mathrm{F}_{1}(P$. pruinosa $\times P$. mínima $), \mathrm{F}_{1}(P$. mínima $\times$ P. angulata $) \mathrm{F}_{1}(P$. angulata $\times P$. ixocarpa $), \mathrm{F}_{1}(P$. pubescens $\times P$. mínima $), \mathrm{F}_{1}(P$. peruviana $\times P$. mínima $), \mathrm{F}_{1}(P$. pruinosa $\times P$. angulata $), \mathrm{F}_{1}(P$. angulata $\times P$. pubescens $), \mathrm{F}_{1}(P$. pubescens $\times P$. ixocarpa $), \mathrm{F}_{1}(P$. mínima $\times P$. pruinosa $), \mathrm{F}_{1}(P$. peruviana $\times P$. ixocarpa $), \mathrm{F}_{1}(P$. angulata $\times P$. peruviana). O Grupo (V) foi formado pela espécie $P$. angulata e os híbridos $\mathrm{F}_{1}(P$. angulata $\times P$. peruviana $), \mathrm{F}_{1}(P$. pruinosa $\times$ $P$. pubescens $), \mathrm{F}_{1}(P$. angulata $\times P$. pruinosa $), \mathrm{F}_{1}(P$. mínima $\times P$. pubescens $)$ e $\mathrm{F}_{1}(P$. angulata $\times P$. mínima $)$. Este último grupo se caracteriza por apresentar as maiores médias para as características NN e NL e para os demais parâmetros com valores intermediários. 
Figura 2. Heatmap com agrupamento hierárquico pelo método de Ward para parâmetros quantitativos das espécies e híbridos de Physalis. Diâmetro da haste principal (MDD), número de hastes laterais (NLH), número de nós (NN), altura da planta (STL), comprimento do entrenó (CE), número de folhas (NL), comprimento da folha (CL) largura da folha (LL), comprimento do estigma (LS), número de flores por racemo (NRF), número de frutos (NF), produção de frutos (PF), massa média de frutos (MF), diâmetro vertical (DV), diâmetro horizontal (DH), número de sementes (NS), sólidos solúveis totais (SS) e massa seca de frutos (MSF). A escala de cores à direita é resultante da normalização dos dados e a intensidade está relacionada às cores quentes e frias referente aos níveis superiores e inferiores à média padronizada, respectivamente. 1. F1(P. pubescens $\times$ P. angulata), 2. F1 $(P$. peruviana $\times$ P. pubescens $)$, 3. F1 $(P$. peruviana $\times$ P. pruinosa $)$, 4. F1 $(P$. pubescens $\times$ P. pruinosa $)$, 5. F1 $(P$. ixocarpa $\times P$. pruinosa $)$, 6. F1 $(P$. ixocarpa $\times P$. mínima $)$, 7. F1 $(P$. ixocarpa $\times P$. angulata $), 8$. F1 $(P$. pubescens $\times P$. mínima $), 9$. F1 $(P$. mínima $\times P$. angulata $), 10 . \mathrm{F} 1(P$. peruviana $\times$ P. mínima $)$, 11. F1 $(P$. angulata $\times P$. peruviana $)$, 12. F1 $(P$. mínima $\times P$. pubescens $), 13$. $\mathrm{F} 1(P$. pruinosa $\times P$. pubescens $)$, 14. F1 $(P$. pruinosa $\times P$. angulata $), 15$. F1 $(P$. pruinosa $\times P$. mínima $), 16$. F1 $(P$. angulata $\times P$. ixocarpa $)$ 17. F1( $P$. angulata $\times$ P. pruinosa $),$ 18. F1 $(P$. angulata $\times$ P. mínima $)$, 19. F1 $(P$. pubescens $\times P$. peruviana $), 20$. F1 $(P$. pubescens $\times P$. ixocarpa $),$ 21. F1 $(P$. mínima $\times P$. pruinosa $)$, 22. F1 $(P$. peruviana $\times P$. ixocarpa $), 23$. F1 $(P$. angulata $\times P$. pubescens), 24. F1(P. daturifolia $\times$ P. ixocarpa), 25. F1(P. daturifolia $\times$ P. angulata), 26. F1(P. daturifolia $\times$ P. peruviana), 27. F1(P. daturifolia $\times$ P. pubescens $),$ 28. F1(P. peruviana $\times$ P. angulata), 29. F1(P. angulata $\times$ P. peruviana $).$

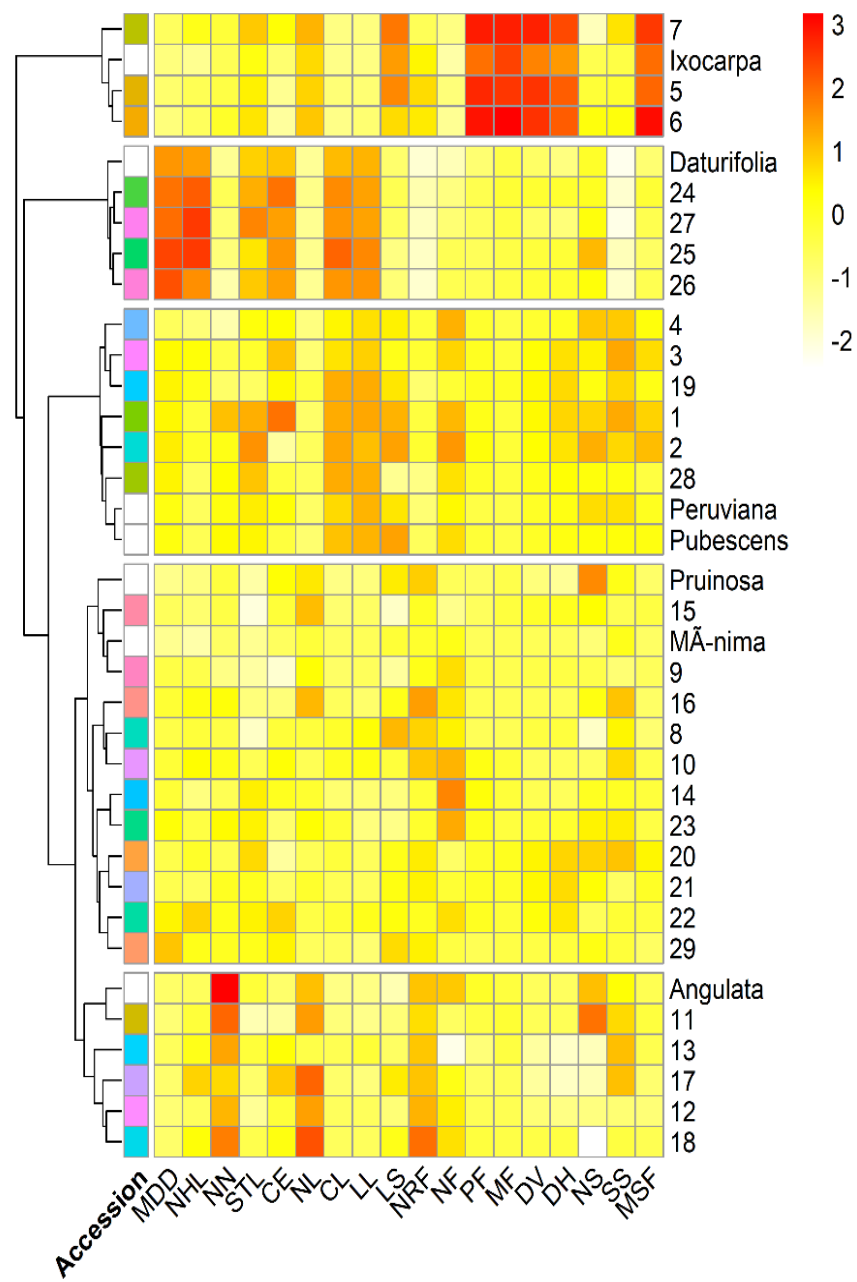

Fonte: Autores. 


\subsection{Análise de componentes principais de parâmetros quantitativos}

A fim de identificar as características mais importantes incluídas em nosso banco de dados desenvolvido, usamos a análise PCA, que permite a análise estatística multivariada de um conjunto de dados. A análise de componentes principais (PCA) explicou 63.01\% da variação total existente entre as sete espécies e os 29 híbridos de Physalis por meio dos dois primeiros componentes principais (PC1 e PC2, respectivamente) (Figura 3). Os resultados observados na PCA foram concordantes aos relatados pelo Heatmap, uma vez que foi possível observar distinção clara das sete espécies e dos 29 híbridos de Physalis nos cincos grupos diferentes. Em relação à contribuição relativa das características para divergência genética entre os híbridos, as características avaliadas MDD, DH, DV, MSF, MF, PF e NRF apresentaram melhores contribuições de $7.5 \%$. Para as características LL, NHL, CE e STL apresentaram contribuições similares de $5 \%$. As demais características avaliadas NS, NF, $\mathrm{NN}$ e FF tiveram o menor valor de contribuição variando entre 2.5 a $3 \%$. Esses aspectos indicam que no presente estudo, as características com contribuições entre 5 a 7.5\% foram importantes para estimar a divergência genética em híbridos de Physalis.

Figura 3. Análise de componentes principais quantitativos das espécies e os híbridos de Physalis. Diâmetro da haste principal (MDD), número de hastes laterais (NLH), número de nós (NN), altura da planta (STL), comprimento do entrenó (CE), número de folhas (NL), comprimento da folha (CL) largura da folha (LL), comprimento do estigma (LS), número de flores por racemo (NRF), número de frutos (NF), produção de frutos (PF), massa média de frutos (MF), diâmetro vertical (DV), diâmetro horizontal (DH), número de sementes (NS), sólidos solúveis (SS) e massa seca de frutos (MSF). 1. F1(P. pubescens $\times$ P. angulata), 2. F1 $(P$. peruviana $\times P$. pubescens $)$, 3. F1 $(P$. peruviana $\times P$. pruinosa $)$, 4. F1 $(P$. pubescens $\times P$. pruinosa $)$, 5. F1( $P$. ixocarpa $\times P$. pruinosa), 6. $\mathrm{F} 1(P$. ixocarpa $\times$ P. mínima $)$, 7. $\mathrm{F} 1(P$. ixocarpa $\times P$. angulata $)$, 8. $\mathrm{F} 1(P$. pubescens $\times P$. mínima $)$, 9. $\mathrm{F} 1(P$. mínima $\times P$. angulata $)$ 10. $\mathrm{F} 1(P$. peruviana $\times P$. mínima $)$, 11. $\mathrm{F} 1(P$. angulata $\times P$. peruviana $)$, 12. $\mathrm{F} 1(P$. mínima $\times P$. pubescens $), 13$. $\mathrm{F} 1(P$. pruinosa $\times P$. pubescens $)$, 14. F1 $(P$. pruinosa $\times P$. angulata $)$, 15. F1 $(P$. pruinosa $\times P$. mínima $)$, 16. F1 $(P$. angulata $\times P$. ixocarpa), 17. $\mathrm{F} 1(P$. angulata $\times P$. pruinosa $)$, 18. $\mathrm{F} 1(P$. angulata $\times P$. mínima $)$, 19. $\mathrm{F} 1(P$. pubescens $\times P$. peruviana $), 20$. $\mathrm{F} 1(P$. pubescens $\times P$. ixocarpa), 21. F1 $(P$. mínima $\times P$. pruinosa $)$, 22. F1 $(P$. peruviana $\times P$. ixocarpa $)$, 23. F1 $(P$. angulata $\times P$. pubescens), 24. F1( $P$. daturifolia $\times P$. ixocarpa), 25. F1( $P$. daturifolia $\times P$. angulata), 26. F1( $P$. daturifolia $\times P$. peruviana), 27. F1( $P$. daturifolia $\times P$. pubescens $),$ 28. F1 $(P$. peruviana $\times P$. angulata $)$, 29. F1( $P$. angulata $\times P$. peruviana $).$

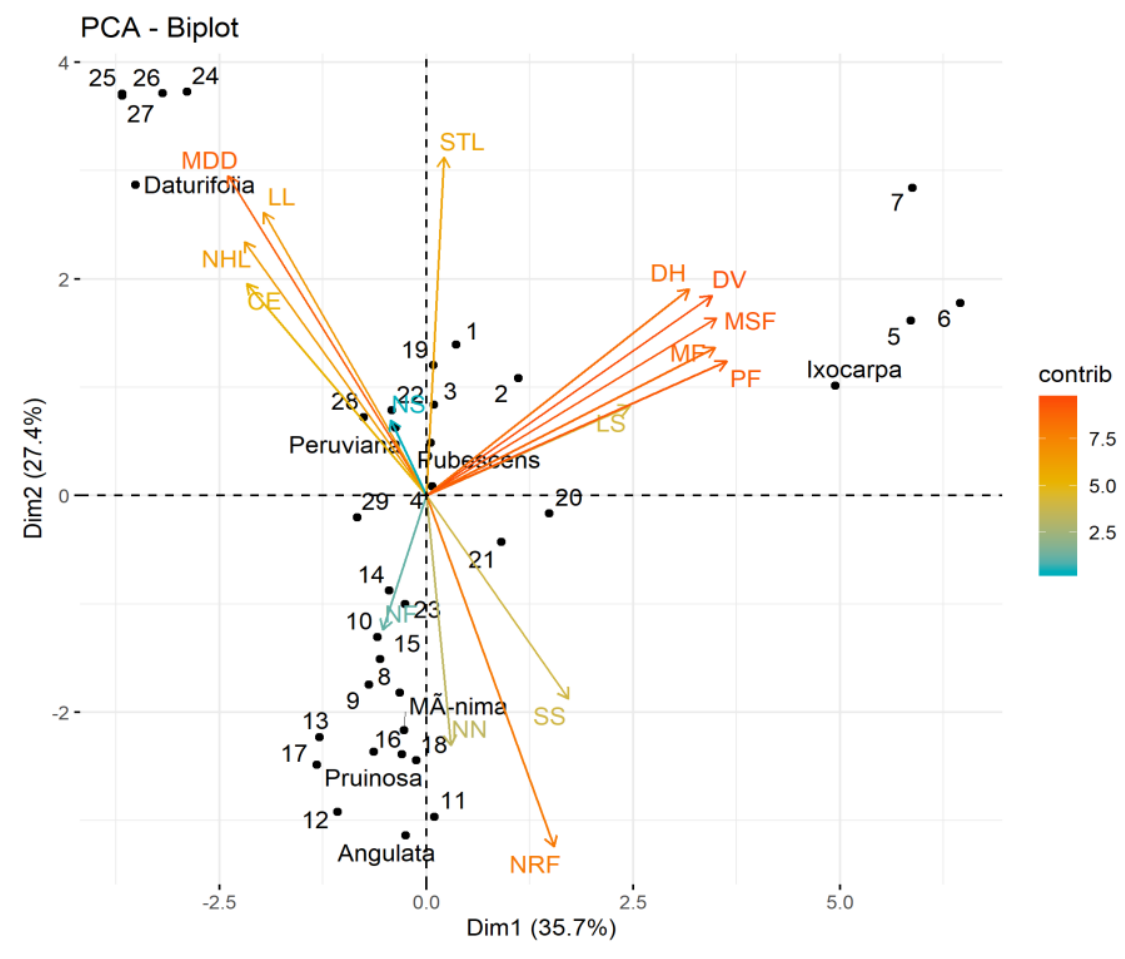

Fonte: Autores. 


\subsection{Correlação entre as características morfoagronômicas quantitativas}

Os resultados da análise de correlação de Spearman (Figura 4), revelaram correlação positiva entre dos parâmetros STL, CE, NL, CL, LL, LS, MF, DV, DH e MSF (0.53, 0.96, 0.94, 0.84 e 0.92 respectivamente) com PF. Ao observar o MDD ocorre um incremento quando correlacionado aos parâmetros NHL, STL, CE, CL e LL (0.81, 0.59, 0.64, 0.84 e 0.77 respectivamente). Já para os parâmetros NN, NL, LS, NRF, NF, PF, MSF (0.38, 0.25, 0.40, 0.52, 0.37, 0.18, 0.26, respectivamente) foram correlacionados positivamente com SS. Correlações negativas foram observadas para NF, quando melhorado os parâmetros NHL, MF, DV e MSF (-0.26, -0.43, -0.24, -0.22, respectivamente). Entretanto, houve correlação positiva para NF quando melhorado os parâmetros NN, CL, LL, NRF e SS (0.20, 0.11, 0.09, 0.16 e 0.37).

Figura 4. Matriz das correlações de postos de Spearman dos parâmetros quantitativos significativos a 5\% pelo teste t de espécies e híbridos de Physalis. Diâmetro da haste principal (MDD), número de hastes laterais (NLH), número de nós (NN), altura da planta (STL), comprimento do entrenó (CE), número de folhas (NL), comprimento da folha (CL) largura da folha (LL), comprimento do estigma (LS), número de flores por racemo (NRF), número de frutos (NF), produção de frutos (PF), massa média de frutos (MF), diâmetro vertical (DV), diâmetro horizontal (DH), número de sementes (NS), sólidos solúveis totais (SS), massa seca de frutos (MSF).

\begin{tabular}{|c|c|c|c|c|c|c|c|c|c|c|c|c|c|c|c|c|c|c|}
\hline 1.00 & 0.81 & -0.39 & 0.59 & 0.64 & -0.71 & 0.84 & 0.77 & -0.22 & -0.80 & -0.07 & -0.31 & -0.29 & -0.16 & -0.09 & 0.24 & -0.57 & -0.23 & MDD \\
\hline 0.81 & 1.00 & -0.22 & 0.41 & 0.65 & -0.37 & 0.61 & 0.54 & -0.20 & -0.52 & -0.26 & -0.27 & -0.20 & -0.20 & -0.21 & -0.04 & -0.54 & -0.24 & NHL \\
\hline-0.39 & -0.22 & 1.00 & -0.21 & -0.20 & 0.54 & -0.35 & -0.36 & -0.11 & 0.58 & 0.20 & -0.06 & -0.11 & -0.20 & -0.21 & -0.06 & 0.38 & -0.11 & NN \\
\hline 0.59 & 0.41 & -0.21 & 1.00 & 0.33 & -0.53 & 0.56 & 0.50 & 0.21 & -0.59 & -0.02 & 0.31 & 0.26 & 0.36 & 0.39 & 0.20 & -0.22 & 0.41 & STL \\
\hline 0.64 & 0.65 & -0.20 & 0.33 & 1.00 & -0.45 & 0.59 & 0.60 & -0.03 & -0.52 & -0.09 & -0.32 & -0.29 & -0.26 & -0.24 & -0.08 & -0.31 & -0.25 & CE \\
\hline-0.71 & -0.37 & 0.54 & -0.53 & -0.45 & 1.00 & -0.77 & -0.78 & 0.04 & 0.72 & -0.04 & 0.29 & 0.30 & 0.13 & 0.01 & -0.33 & 0.25 & 0.13 & NL \\
\hline 0.84 & 0.61 & -0.35 & 0.56 & 0.59 & -0.77 & 1.00 & 0.97 & -0.06 & -0.78 & 0.11 & -0.32 & -0.35 & -0.15 & -0.03 & 0.29 & -0.30 & -0.15 & $\mathrm{CL}$ \\
\hline 0.77 & 0.54 & -0.36 & 0.50 & 0.60 & -0.78 & 0.97 & 1.00 & -0.00 & -0.76 & 0.09 & -0.30 & -0.32 & -0.13 & -0.01 & 0.22 & -0.27 & -0.12 & LL \\
\hline-0.22 & -0.20 & -0.11 & 0.21 & -0.03 & 0.04 & -0.06 & -0.00 & 1.00 & 0.17 & -0.02 & 0.53 & 0.49 & 0.57 & 0.56 & -0.15 & 0.40 & 0.61 & LS \\
\hline-0.80 & -0.52 & 0.58 & -0.59 & -0.52 & 0.72 & -0.78 & -0.76 & 0.17 & 1.00 & 0.16 & 0.11 & 0.08 & -0.05 & -0.10 & -0.31 & 0.52 & 0.00 & NRF \\
\hline-0.07 & -0.26 & 0.20 & -0.02 & -0.09 & -0.04 & 0.11 & 0.09 & -0.02 & 0.16 & 1.00 & -0.18 & -0.43 & -0.24 & -0.10 & 0.11 & 0.37 & -0.22 & NF \\
\hline-0.31 & -0.27 & -0.06 & 0.31 & -0.32 & 0.29 & -0.32 & -0.30 & 0.53 & 0.11 & -0.18 & 1.00 & 0.96 & 0.94 & 0.84 & -0.10 & 0.18 & 0.92 & PF \\
\hline-0.29 & -0.20 & -0.11 & 0.26 & -0.29 & 0.30 & -0.35 & -0.32 & 0.49 & 0.08 & -0.43 & 0.96 & 1.00 & 0.91 & 0.78 & -0.14 & 0.06 & 0.90 & MF \\
\hline-0.16 & -0.20 & -0.20 & 0.36 & -0.26 & 0.13 & -0.15 & -0.13 & 0.57 & -0.05 & -0.24 & 0.94 & 0.91 & 1.00 & 0.97 & -0.01 & 0.11 & 0.93 & DV \\
\hline-0.09 & -0.21 & -0.21 & 0.39 & -0.24 & 0.01 & -0.03 & -0.01 & 0.56 & -0.10 & -0.10 & 0.84 & 0.78 & 0.97 & 1.00 & 0.09 & 0.16 & 0.88 & $\mathrm{DH}$ \\
\hline 0.24 & -0.04 & -0.06 & 0.20 & -0.08 & -0.33 & 0.29 & 0.22 & -0.15 & -0.31 & 0.11 & -0.10 & -0.14 & -0.01 & 0.09 & 1.00 & 0.04 & 0.04 & NS \\
\hline-0.57 & -0.54 & 0.38 & -0.22 & -0.31 & 0.25 & -0.30 & -0.27 & 0.40 & 0.52 & 0.37 & 0.18 & 0.06 & 0.11 & 0.16 & 0.04 & 1.00 & 0.26 & SS \\
\hline-0.23 & -0.24 & -0.11 & 0.41 & -0.25 & 0.13 & -0.15 & -0.12 & 0.61 & 0.00 & -0.22 & 0.92 & 0.90 & 0.93 & 0.88 & 0.04 & 0.26 & 1.00 & MSF \\
\hline סه, & $\lambda^{2}$ & 5 & $\mathrm{c}^{2}$ & o & $s^{2}$ & $\mathrm{O}^{2}$ & $v$ & 5 & & 5 & $Q^{x}$ & $\leqslant$ & 8 & $0^{\lambda}$ & s & $5^{5}$ & st & \\
\hline
\end{tabular}




\section{Discussão}

O principal objetivo da presente pesquisa foi explorar parâmetros morfoagronômicos de híbridos interespecíficos de Physalis visando contribuir para programas de melhoramento futuros. A ausência de correlação observada no agrupamento formado pelo método de Ward (Figura 1) obtido a partir das matrizes de distância, utilizando as características quantitativas e qualitativas já foram relatadas em diversas espécies, confirmando a importância de ambas as caracterizações para um melhor compreendimento da diversidade genética entre os genótipos avaliados (Delfini et al., 2017; Melão et al., 2015; Vieira et al., 2013). O agrupamento tem por finalidade reunir os genótipos em grupos, de tal forma que exista homogeneidade dentro do grupo e heterogeneidade entre grupos (Cruz et al., 2011). Segundo Gonçalves et al., (2008) e com base em rediscussão de Tsivelikas et al., (2009), a análise conjunta dos dados quantitativos e qualitativos pode fornecer uma melhor compreensão da diversidade genética do banco germoplasma e também verificar se a evidência total está dentro dos limites de confiança dos elementos de cada conjunto de dados, contribuindo para estratégias de melhoramento futuras (Costa et al., 2012; Ganga et al., 2004; Viana et al., 2003). Ao analisar uma ampla gama de características qualitativas e quantitativas, o presente estudo demonstra uma considerável amplitude de diferentes características marcantes das espécies e dos híbridos de Physalis. Esses parâmetros são de relevância para programas de melhoramento genético e confirmam resultados de estudos anteriores, que destacaram imensa variabilidade genética das espécies (Bogotá, 2011). A técnica de agrupamento minimiza a variabilidade dentro do grupo. Entretanto, se a estimativa de distância entre pares de indivíduos dentro do grupo é de elevada magnitude, justifica-se o subcluster (Flávia et al., 2004). Os subcluster formados são encontrados em boa parte os resultados na literatura (Allem, 2002; Chacón et al., 2008; Duputié et al., 2011). É importante ressaltar que cada conjunto de dados, seja quantitativo, seja qualitativo, tem suas vantagens e desvantagens para análise (Mohammadi \& Prasanna, 2003) e muitos dados têm sido gerados, demonstrando a importância de se conhecer esses descritores (Lotti et al., 2008).

Com o uso de Heatmap (Figura 2) foi possível identificar a estrutura hierárquica de agrupamentos de linha e coluna das matrizes de dados, sendo um método fácil e intuitivo para definir matematicamente a similaridade entre as variáveis avaliadas com base na distância euclidiana (Rebouças et al., 2018; Uarrota et al., 2014). Chamados de Cluster Heatmaps, tais figuras funcionam como display, onde colunas e linhas caracterizam as espécies e os híbridos de Physalis, representados por cada célula colorida com base no nível de parentesco, e maiores valores obtidos entre as plantas (Higa et al., 2010). Com a análise do mapa de calor (Heatmap) com agrupamento hierárquico pelo método de Ward no presente estudo, observou-se a formação de cinco grupos. A identificação dos grupos, é de extrema importância para a escolha dos progenitores que serão utilizados nos programas de melhoramento (Biswas et al., 2018; Nerling et al., 2018). De acordo com Santos et al., (2012), os genótipos do mesmo grupo são geneticamente semelhantes e suas combinações podem causar variabilidade inferior em comparação aos demais grupos. Já nos grupos distantes, são indiciadores de tornarem-se divergentes genéticas e podendo ser consideradas promissoras em cruzamentos artificiais. Por exemplo, genótipos presente no Grupo I com maior medias em NL, LS, PF, MF, DV, DH e MSF, poderiam ser utilizados em novo programa de reprodução para melhoria dessas características, em outras plantas de Physalis que possuem inferioridade das características supracitadas, como no Grupo III, IV, e V. O mesmo aspecto seria para o grupo II, com maior medias para as características MDD, NHL, STL, CE, CL e LL. Alguns estudos presentes na literatura caracterizaram parâmetros morfoagronomicos da espécie de Physalis peruviana na colômbia e Equador, visando contribuir para programas de melhoramentos futuros (Pulgarín, 1989; González et al., 2008). O mesmo estudo foi realizado para a espécies Physalis angulata avaliando os atributos agromorfológicos (Saavedra et al., 2019). Porém, dados sobre parâmetros morfoagronomicos de várias espécies de Physalis e seus respectivos híbridos eram inexistentes até então, com isso os resultados obtidos neste estudo possivelmente serão do interesse de trabalhos que visam aumentar a eficiência de cruzamentos artificias para formação de novos genótipos que sejam mais promissores. Trabalhos semelhantes realizados visaram identificar genótipos superiores que possam ser utilizados como base nos programas de melhoramento (Herrera Moreno et al., 2012; Trevisani et al., 2016). Como resultado 
dessa seleção, cultivares como 'Golden Nugget' e 'New Sugar Giant' são descritas na Austrália, e 'Peace', 'Giant Groundcherry', 'Goldenberry', 'Giallo Grosso', 'Giant', 'Giant Poha Berry', 'Golden Berry' e 'Golden Berry-Long Ashton' são oriundas de programas de melhoramento americanos (Fischer, 2000; Fischer et al., 2014).

A fim de identificar as características quantitativas mais importantes incluídas nos Physalis, usamos a análise PCA (Figura 3). Metodologia de destaque como a mais empregada nos bancos e coleções germoplasmas. A análise de componentes principais além de identificar os caracteres mais relevantes na contribuição para a variação total disponível entre os indivíduos analisados, fornece indicação para eliminar os que pouco contribuem (Alves, 2002; Dias et al., 1997). Os resultados da PCA (Figura 3) no presente estudo, revelaram que as variáveis MDD, DH, DV, MSF, MF, PF, NRF, LL, NHL, CE e STL, tiveram maior contribuições na melhoria das espécies de Physalis. E também revelaram vários genótipos como potenciais pais ótimos para o desenvolvimento de novas espécies de Physalis, com potenciais superiores aos seus genitores. Estudos relataram a importância da análise PCA, sendo utilizada para orientar trabalhos de melhoramento genético visando obter sucesso nas escolhas dos futuros genitores (Balkaya et al., 2010; Borges et al., 2011; Lu et al., 2019; Varmuza \& Filzmoser, 2009). Segundo Carvalho et al. (2004), o coeficiente de correlação significativo refere-se a um indicativo de associação entre variáveis. Da mesma forma, coeficiente de correlação baixa não demonstra falta de associação entre caracteres, mas sim a inexistência de relação casual.

Certamente, os resultados obtidos no presente trabalho a respeito dos parâmetros morfoagronômicos, são do interesse de programas de melhoramento genético, podendo contribuir com as informações já presentes em literatura e constituir uma importante base científica para o desenvolvimento de novos estudos.

\section{Conclusão}

No presente estudo os genótipos de Physalis foram caracterizados em vários agrupamentos com base em características morfológicas. Com as avaliações foi possível observar a formação de cinco grupos quantitativos e qualitativos distintos, fornecendo características com maior relevância de cada genótipo ajudando pesquisas futuras em melhoria da espécie. Os híbridos de Physalis foram superiores para maioria das variáveis quantitativas, demonstrando que seus genitores têm potencial para desenvolvimento de novos genótipos.

A partir dos resultados obtidos neste trabalho, novos estudos podem ser realizados, para obtenção e seleção de genótipos de Physalis superiores, visando principalmente um aumento na qualidade de frutos e da produtividade.

\section{Agradecimentos}

Os autores agradecem à Fundação de Amparo à Pesquisa do Estado de São Paulo (FAPESP) pelo apoio por meio de bolsa concedida ao primeiro autor (Processo 2019/15378-5).

\section{Referências}

Abdel, G. A. H., Neumann, K., Wabila, C., Sharma, R., Dhanagond, S., Owais, S. J., Börner, A., Graner, A., \& Kilian, B. (2015). Diversity of germination and seedling traits in a spring barley (Hordeum vulgare L.) collection under drought simulated conditions. Genetic Resources and Crop Evolution, 62(2), 275-292.

Abreu, F. B. (2005). Herança da resistência a Phytophthora infestans, de características de frutos e seleção de genótipos resistentes na geração F5 de cruzamento interespecífico em tomateiro.

Abreu, F. B., Leal, N. R., Rodrigues, R., Amaral Júnior, A. T. do, \& da Silva, D. J. (2004). Divergência genética entre acessos de feijão-de-vagem de hábito de crescimento indeterminado. Horticultura Brasileira, (22), 547-552.

Aliero, A. A., \& Usman, H. (2016). Leaves of Ground Cherry (Physalis angulata L.) May Be Suitable in Alleviating Micronutrient Deficiency. Food Science and Technology, 4(5): 89-94.

Allem, A. C. (2002). The origins and taxonomy of cassava. Cassava: biology, production and utilization, $1,16$. 
Alves, R. M. (2002). Caracterização genética de populações de cupuaçuzeiro, Theobroma grandiflorum (Willd. Ex. Spreng.) Schum., por marcadores microssatélites e descritores botânico-agronômicos. Universidade de São Paulo.

Araujo, F. L. (2012). Estudo genético e citogenético de duas espécies do gênero Physalis (Solanaceae).

Azeez, S., \& FALUYI, J. (2018). Hybridization in Four Nigerian Physalis (Linn.) Species. Notulae Scientia Biologicae, 10(2):205-210.

Balkaya, A., Özbakir, M., \& Kurtar, E. S. (2010). The phenotypic diversity and fruit characterization of winter squash (Cucurbita maxima) populations from the Black Sea Region of Turkey. African Journal of Biotechnology, 9(2).

Benito-Bautista, P., Arellanes-Juárez, N., \& Pérez-Flores, M. E. (2016). Color y estado de madurez del fruto de tomate de cáscara. Agronomía Mesoamericana, $27(1), 115-130$.

Biswas, M. K., Nath, U. K., Howlader, J., Bagchi, M., Natarajan, S., Kayum, M. A., Kim, H.T., Park, J.-I., Kang, J. G., \& Nou, I.S. (2018). Exploration and exploitation of novel SSR markers for candidate transcription factor genes in Lilium species. Genes, 9(2), 97.

Bogotá, C. C. (2011). Producción de plantas genéticamente puras de uchuva physalis peruviana.

Bonilla, B. M. L., Piedrahíta, E. K., Posso Terranova, A. M., Vásquez, A. H. D., \& Muñoz F. J. E. (2008). Caracterizacion morfológica de 24 accesiones de uchuva del banco de germoplasma de la Universidad Nacional de Colombia Sede Palmira. Acta Agronómica, 57(2), 101-108.

Borges, R. M. E., Resende, G. M., Lima, M. A. C., Dias, R. de C. S., Lubarino, P. C. C., Oliveira, R. C. S., \& Gonçalves, N. P. S. (2011). Phenotypic variability among pumpkin accessions in the Brazilian semiarid. Horticultura Brasileira, 29, 461-464.

Carmona, P. A., Peixoto, J. R., Amaro, G. B., Mendonça, M. A., Carmona, P. A., Peixoto, J. R., Amaro, G. B., \& Mendonça, M. A. (2015). Genetic divergence of sweet potato accessions based on morpho-agronomic descriptors of the roots. Horticultura Brasileira, 33(2), 241-250.

Cely, J. A. B., Rodríguez, F. E., Almario, C. G., \& Meneses, L. S. B. (2015). Variabilidade genética de parentales y Poblaciones f1 inter e intraespecíficas de Physalis peruviana L. Y P. Revista Brasileira de Fruticultura, 37, 179-192.

Chacón, J., Madriñán, S., Debouck, D., Rodriguez, F., \& Tohme, J. (2008). Phylogenetic patterns in the genus Manihot (Euphorbiaceae) inferred from analyses of nuclear and chloroplast DNA regions. Molecular Phylogenetics and Evolution, 49(1), 260-267.

Costa, A. M., Spehar, C. R., \& Sereno, J. R. B. (2012). Conservação de recursos genéticos no Brasil. Embrapa Cerrados-Livro científico.

Cruz, C. D., Ferreira, F. M., \& Pessoni, L. A. (2011). Biometria aplicada ao estudo da diversidade genética. Visconde do Rio Branco: Suprema, 620.

Debbi, A., Boureghda, H., Monte, E., \& Hermosa, R. (2018). Distribution and Genetic Variability of Fusarium oxysporum Associated with Tomato Diseases in Algeria and a Biocontrol Strategy with Indigenous Trichoderma spp. Frontiers in Microbiology, 0.

Carmen, M. S. J., Rodríguez Z. F. A., Cabrera, T. D., Sánchez H. C. V., \& Vargas, P. O. (2019). Agromorphological characterization of wild and weedy populations of Physalis angulata in Mexico. Scientia Horticulturae, 246, 86-94.

Delfini, J., Moda, C., V., Ruas, C. de F., Neto, J. dos S., Ruas, P. M., Buratto, J. S., Ruas, E. A., \& Gonçalves, L. S. A. (2017). Distinctness of Brazilian common bean cultivars with carioca and black grain by means of morphoagronomic and molecular descriptors. PLoS ONE 12(11): e0188798.

Dias, L. dos S., Kageyama, P. Y., \& Castro, G. C. T. (1997). Multivariate phenetic divergence in germplasm preservation of cacao (Theobroma cacao L.). AGROTROPICA, 9, 29-40.

Duputié, A., Salick, J., \& McKey, D. (2011). Evolutionary biogeography of Manihot (Euphorbiaceae), a rapidly radiating Neotropical genus restricted to dry environments. Journal of Biogeography, 38(6), 1033-1043.

Fischer, G. (2000). Crecimiento y desarrollo. Producción, poscosecha y exportación de la uchuva, 9-26.

Fischer, G., Almanza, M. P. J., \& Miranda, D. (2014). Importancia y cultivo de la uchuva (Physalis peruviana L.). Revista Brasileira de Fruticultura, 36(1), 0115.

Fufa, H., Baenziger, P. S., Beecher, B. S., Dweikat, I., Graybosch, R. A., \& Eskridge, K. M. (2005). Comparison of phenotypic and molecular marker-based classifications of hard red winter wheat cultivars. Euphytica, 145(1), 133-146.

Fukushima, A., Nakamura, M., Suzuki, H., Yamazaki, M., Knoch, E., Mori, T., Umemoto, N., Morita, M., Hirai, G., Sodeoka, M., \& Saito, K. (2016). Comparative Characterization of the Leaf Tissue of Physalis alkekengi and Physalis peruviana Using RNA-seq and Metabolite Profiling. Frontiers in Plant Science, 7:1883.

Ganga, R. M. D., Ruggiero, C., Lemos, E. G. de M., Grili, G. V. G., Gonçalves, M. M., Chagas, E. A., \& Wickert, E. (2004). Diversidade genética em maracujazeiro-amarelo utilizando marcadores moleculares Faflp. Revista Brasileira de Fruticultura, 26, 494-498.

Gonçalves, L. S. A., Rodrigues, R., AMARAL JÚNIOR, A. Karasawa, M., \& Sudré, C. P. (2008). Comparison of multivariate statistical algorithms to cluster tomato heirloom accessions. Genetics and Molecular Research, 7(4), 1289-1297.

González, O., Cotes, T. J. M., Medina, C. C. I., Lobo, A. M., \& Navas, A. A. (2008). Caracterización morfológica de cuarenta y seis accesiones de uchuva (Physalis peruviana L.), en Antioquia (Colombia). Revista Brasileira de Fruticultura, 30, 708-715.

Herrera, M. A., Fischer, G., \& Chacon Sánchez, M. I. (2012). Agronomical evaluation of cape gooseberries (Physalis peruviana L.) from central and northeastern colombia. Agronomía Colombiana. 
Higa, R. H., Almeida, R. L. C., Ibelli, A. M. G., \& Santos, I. L. N. (2010). Estudo de algoritmos de biclustering para a análise de expressão gênica utilizando a tecnologia de microarranjo. Embrapa Informática Agropecuária-Documentos, 1677-9274.

Lê, S., Josse, J., \& Husson, F. (2008). FactoMineR: An R package for multivariate analysis. Journal of statistical software, 25(1), 1-18.

Lotti, C., Marcotrigiano, A. R., De Giovanni, C., Resta, P., Ricciardi, A., Zonno, V., Fanizza, G., \& Ricciardi, L. (2008). Univariate and multivariate analysis performed on bio-agronomical traits of Cucumis melo L. germplasm. Genetic Resources and Crop Evolution, 55(4), 511-522.

Lu, L., Luo, T., Zhao, Y., Cai, C., Fu, Z., \& Jin, Y. (2019). Interaction between microplastics and microorganism as well as gut microbiota: A consideration on environmental animal and human health. Science of the Total Environment, 667, 94-100.

Maechler, M., Rousseeuw, P., Struyf, A., Hubert, M., Hornik, K., Studer, M., Roudier, P., Gonzalez, J., Kozlowski, K., \& Schubert, E. (2019). Package cluster: Finding Groups in Data: Cluster Analysis Extended. R package version 2.1. 0.

Martínez, M. (1998). Revisión de Physalis sección Epiteiorhiza (Solanaceae). Anales del Instituto de Biología. Serie Botánica, 69(2), 71-117.

Medina, M. J. R., Almaraz, A. N., González, E. M. S., Uribe, S. J. N., González, V. L. S., \& Herrera, A. Y. (2015). Phenolic constituents and antioxidant properties of five wild species of Physalis (Solanaceae). Botanical studies, 56(1), 1-13.

Melão, A. V., Pereira, M. G., Krause, W., Gonçalves, L. S. A., \& Moreira, W. G. (2015). Caracterização agronômica e divergência genética entre acessos de abacaxizeiro nas condições do estado de Mato Grosso. Revista Brasileira de Fruticultura, 37, 952-960.

Mohammadi, S. A., \& Prasanna, B. M. (2003). Analysis of genetic diversity in crop plants—Salient statistical tools and considerations. Crop science, 43(4), $1235-1248$

Nahak, S. C., Nandi, A., Sahu, G. S., Tripathy, P., Dash, S. K., Patnaik, A., \& Pradhan, S. R. (2018). Studies on variability, heritability and genetic advance for yield and yield contributing characters in chilli (Capsicum annuum L.). J. Pharma. Phytochem, 7(1), 2506-2510.

Nerling, D., Coelho, C. M. M., \& Brümmer, A. (2018). Biochemical profiling and its role in physiological quality of maize seeds. Journal of Seed Science, 40, $07-15$.

Pandey, M. K., Pandey, A. K., Kumar, R., Nwosu, C. V., Guo, B., Wright, G. C., Bhat, R. S., Chen, X., Bera, S. K., \& Yuan, M. (2020). Translational genomics for achieving higher genetic gains in groundnut. Theoretical and Applied Genetics, 133(5), 1679-1702.

Pulgarín, O. (1989). Caracterización fenotípica preliminar de 13 colecciones de uchuva (Physalis peruviana L.). Trabajo de grado (Biólogo). Instituto de Biología, Universidad de Antioquia, Medellín, Colombia.

Rebouças, T. A., Haddad, F., Ferreira, C. F., de Oliveira, S. A. S., da Silva Ledo, C. A., \& Amorim, E. P. (2018). Identification of banana genotypes resistant to Fusarium wilt race 1 under field and greenhouse conditions. Scientia Horticulturae, 239, 308-313.

Salazar, G., M. R., Jones, J., Chaves, B., Cooman, A., \& Fischer, G. (2008). Base temperature and simulation model for nodes appearance in cape gooseberry (Physalis peruviana L.). Revista Brasileira de Fruticultura, 30, 862-867.

Samuels, J. (2015). Biodiversity of food species of the Solanaceae family: A preliminary taxonomic inventory of subfamily Solanoideae. Resources, 4(2), 277322.

Santos, E. R., Barros, H. B., Capone, A., de Melo, A. V., Cella, A. J. S., \& dos Santos, W. R. (2012). Divergência genética entre genótipos de soja com base na qualidade de sementes. Revista Brasileira de Ciências Agrárias, 7(2), 247-254.

Silva, D. F, Pio. R., Micheli, M., Soares, J. D. R., Martins, A. D., \& Nogueira, P. V. (2018). Productive and qualitative parameters of four Physalis species cultivated under colored shade nets. Revista Brasileira de Fruticultura, 40-2.

Silva, D. F, Pio. R., Soares, J. D. R., Nogueira, P. V., Peche, P. M., \& Villa, F. (2016). The production of Physalis spp. Seedlings grown under different-colored shade nets. Acta Scientiarum. Agronomy, 382-257.

Sobral, K. M. B., Ramos, S. R. R., Goncalves, L. S. A., Amaral, J. A. T., \& Aragão, W. M. (2012). Variabilidade genética entre acessos de coqueiro-anão utilizando técnicas de análise multivariada. Magistra, 24(4), 348-359.

Spooner, D., Van, T. R., \& Vicente, M. C. (2005). Molecular markers for genebank management. IPGRI Technical Bulletin No. 10. International Plant Genetic Resources Institute, Rome.

Suescún, L., Sanchez, E., Gómez, M., Garcia, A. F. L., \& Zarantes, V. N. (2011). Producción de plantas genéticamente puras de Uchuva. Editorial Kimpres Ltda., Bogota.

Sun, C.-P., Qiu, C.-Y., Zhao, F., Kang, N., Chen, L.-X., \& Qiu, F. (2017). Physalins V-IX, 16,24-cyclo-13,14-seco withanolides from Physalis angulata and their antiproliferative and anti-inflammatory activities. Scientific Reports, 7(1), 4057.

Team, R. C. (2018). R: A language and environment for statistical computing; 2018.

Trevisani, N., Schmit, R., Beck, M., Guidolin, A. F., \& Coimbra, J. L. M. (2016). Selection of fisális populations for hibridizations, based on fruit traits. Revista Brasileira de Fruticultura, 38.

Tsivelikas, A. L., Koutita, O., Anastasiadou, A., Skaracis, G. N., Traka, M. E., \& Koutsika-Sotiriou, M. (2009). Description and analysis of genetic diversity among squash accessions. Brazilian Archives of Biology and Technology, 52, 271-283. 
Research, Society and Development, v. 11, n. 2, e4311225464, 2022

(CC BY 4.0) | ISSN 2525-3409 | DOI: http://dx.doi.org/10.33448/rsd-v11i2.25464

Uarrota, V. G., Moresco, R., Coelho, B., Nunes, E. C., Peruch, L. A. M., Neubert, E. O., Rocha, M., \& Maraschin, M. (2014). Metabolomics combined with chemometric tools (PCA, HCA, PLS-DA and SVM) for screening cassava (Manihot esculenta Crantz) roots during postharvest physiological deterioration. Food Chemistry, 161, 67-78.

Varmuza, K., \& Filzmoser, P. (2009). Comparison of some linear regression methods - available in R - for a QSPR problem. Chemistry Central Journal, 31, P37.

Viana, A. P., Pereira, T. N. S., Pereira, M. G., Souza, M. M. de, Maldonado, J. F. M., \& Amaral, J. A. T. do. (2003). Diversidade genética entre genótipos comerciais de maracujazeiro-amarelo (Passiflora edulis f. Flavicarpa) e entre espécies de passifloras nativas determinada por marcadores RAPD. Revista Brasileira de fruticultura, 25, 489-493.

Vieira, E. A., de Freitas, F. J., Faleiro, F. G., Bellon, G., Fonseca, K. G., Silva, M. S., de Paula, M. S. V., \& Carvalho, L. J. C. B. (2013). Caracterização fenotípica e molecular de acessos de mandioca de indústria com potencial de adaptação às condições do Cerrado do Brasil Central. Semina: Ciências Agrárias, 34(2), 567581.

Wei, T., Simko, V., Levy, M., Xie, Y., Jin, Y., \& Zemla, J. (2017). Package 'corrplot'. Statistician, 56(316), 24.

Whitson, M., \& Manos, P. S. (2005). Untangling Physalis (Solanaceae) from the Physaloids: A two-gene phylogeny of the Physalinae. Systematic Botany, 30(1), 216-230. 